\title{
Treatment of Long Standing Multiple Sclerosis with Regentime Stem Cell Technique
}

Nassim H Abi Chahine ${ }^{1 *}$, Johny R Rached ${ }^{2}$, Alaa F Abdelkarim ${ }^{3}$, Aline A Hamade ${ }^{4}$ and Victoria V Zoghbi ${ }^{5}$

${ }^{1}$ Neurological Surgery, University of Lodz, Poland and University of Balamand, Lebanon

${ }^{2}$ Cancer Stem Cells Biology, University of Balamand, Lebanon

${ }^{3}$ Endocrinology and Acute Medicine, Cairo University, Egypt and MRCGP, United Kingdom

${ }^{4}$ Department of Life and Earth Sciences, Faculty of Sciences 2, Lebanese University, Lebanon

${ }^{5}$ Anesthesiology and Reanimation, State University Medical Faculty, Nalchik, Russia and Kuban State Medical University, Russia

\begin{abstract}
This article is a case report in which we exposed the results of a multiple sclerosis (MS) patient, treated with stem cells. The 51 year old female patient was presenting with 23 year history of primary progressive type of MS. Her disease was physically debilitating causing numerous permanent complications during its long history, where different medications were used with no improvement; MS was progressing uncontrollably.
\end{abstract}

Autologous bone marrow derived stem cells were outsourcing the procedure of treatment (Regentime ${ }^{\circledR}$ technique) This type of therapy was never previously used on such longstanding MS case and with such advanced impairment.

Twelve main symptoms were studied and monitored during the post therapy care period. The follow up was done for 18 months before the publication of the results.

We noticed a clear improvement at most levels, including a decrease in the headache, fatigue, hypertonia and dizziness. No regression was registered during the post-transplantation follow up period.

We concluded that MS has positively responded to Regentime ${ }^{\circledR}$ procedure stem cell therapy even in its advance longstanding stage. This positive response may be due to the pathophysiological stepping nature of MS, where better improvements are seen in newer calling-for-repair lesions as shown in a previous study.

Keywords: MS (multiple sclerosis); ASCT (autologous stem cell therapy)

\section{Introduction}

Multiple sclerosis (MS) is a progressive disease leading to degradation of the myelin sheath around central axons. Lesions are composed of areas of myelin and oligodendrocyte loss along with infiltrates of inflammatory cells, including lymphocytes and macrophages [1-9]. The degradation of myelin leads to disruption of the electrical neural communication, resulting in a wide range of clinical picture.

Medicine was constantly searching for a treatment to cure MS or to perpetually treat refractory cases which do not respond to conventional therapies. Pharmacological treatments ensure nowadays immune suppression in a way to decrease the severity to maintain the disease in a plateau like behavior $[2,10]$. No curative, FDA-approved therapies for MS are currently available [2].

In a previous study, Abi Chahine et al. demonstrate that early treatment of neurodegenerative diseases is a key factor in the success of bone marrow derived stem cell transplantation [1]. In this case report, an acceptable positive result of ASCT in long standing multiple sclerosis is shown.

\section{Case Presentation}

Authors presented a case of stem cell therapy for a 51 year old woman with longstanding advanced stage multiple sclerosis. Previous pharmacological measures, including immune suppression and immune modulation did not lead to any improvement or to any stabilization; consequently her health deterioration was evolving through 23 years. Several declines were developed. The patient was showing all of the following major symptoms and signs at the pre-transplant examination:
1. Astasis

2. Blurry vision

3. Diplopia

4. Dizziness

5. Dysarthria

6. Dysphagia

7. Headache

8. Hypertonia

9. Neurogenic bladder

10. Paresthesia

11. Spasms

12. Weakness

The patient's treatment during the 5 stages of Regentime technique:

*Corresponding author: Nassim H Abi Chahine, Neurological Surgery, University of Lodz, Poland and University of Balamand, Lebanon, Tel: 009613082498; Fax: 009616951100; E-mail: nassim@wp.eu

Received July 11, 2015; Accepted August 17, 2015; Published August 19, 2015

Citation: Abi Chahine NH, Rached JR, Abdelkarim AF, Hamade AA, Zoghbi VV (2015) Treatment of Long Standing Multiple Sclerosis with Regentime Stem Cell Technique. J Stem Cell Res Ther 5: 299. doi:10.4172/2157-7633.1000299

Copyright: (c) 2015 Abi Chahine $\mathrm{NH}$, et al. This is an open-access article distributed under the terms of the Creative Commons Attribution License, which permits unrestricted use, distribution, and reproduction in any medium, provided the original author and source are credited. 


\section{The pre-lab stage}

24 and 48 hours prior to bone marrow collection, the patient was subcutaneously injected with doses of $600 \mathrm{mcg}$ of Filgrastim along with intramuscular injections of Cerebrolysin $(5 \mathrm{ml} / 8$ hours $)$ and oral Citicholine (1000 mg/8 hours).

\section{The Bone Marrow Collection stage}

Post preparatory stage, bone marrow collection -in a total volume of $200 \mathrm{ml}$ - was done under local anesthesia, bilaterally, from both superior posterior iliac crests, using a $1.5 \mathrm{~mm}$ collecting needle, as described by Regentime procedure $^{1}$. The aspirate was smoothly mixed with 25000 IU of Heparin and transported to the laboratory. A pre-lab incubation of 6 hours at $4-8^{\circ} \mathrm{C}$ preceded the partition procedure. During the mentioned phase, the bone marrow aspirate was softly injected into a transfusion bag filled with $20 \mathrm{ml}$ of sodium citrate.

\section{The Laboratory stage}

$200 \mathrm{ml}$ of bone marrow extract was centrifuged at $200 \mathrm{G}$ for 10 minutes. $6 \mathrm{ml}$ of buffy coat was collected. Moreover the final product included $2 \mathrm{ml}$ of highly purified plasma and $2 \mathrm{ml}$ of red blood cells, making in all $10 \mathrm{ml}$.

This product was equally divided into two tubes:

Tube 1: mixed with rabbit fetus central nervous system ultrafiltrate (MF3 SWISS | LABDOM).

Tube 2: Left with no additions.

Both tubes were placed on shaker, for another incubation period of 18 hours, at $20-24^{\circ} \mathrm{C}$.

\section{The transplantation stage}

The treatment started with a lumbar puncture in prone position. 4 $\mathrm{ml}$ of cerebrospinal fluid were drained out and replaced with the $5 \mathrm{ml}$ content of tube 2. Directly after the intrathecal injection, the patient was placed in Trendelenburg position of 10 degrees angle. This step was followed by an intravenous bolus infusion of $200 \mathrm{ml}$ of Mannitol 20\% and, 30 minutes later, when the diuretic effect of Mannitol has started; an intravenous rapid infusion of tube 1 content was done.

\section{The post-transplantation stage}

The patient was subjected to 10 hours Trendelenburg position of 10 degrees angle. The next 24 hours after the transplantation included $1000 \mathrm{mg}$ of rapid intravenous instillation of Citicholine every 8 hours and $10 \mathrm{ml}$ of slow intravenous dripping of Cerebrolysin every 8 hours.

Excessive urination caused by the Mannitol infusion subsided during the first hours. Light headache and nausea were treated with an intravenous metoclopramid, only 2 consecutive doses were given. After discharge from the hospital, the patient was on the following medications:

\section{Citicholine}

$$
\begin{aligned}
& \text { Dose: } 1000 \mathrm{mg} \\
& \text { Route: oral (drinkable ampules) } \\
& \text { Frequency: twice daily } \\
& \text { Duration: } 10 \text { days }
\end{aligned}
$$

\section{Cerebrolysin}

Dose: $5 \mathrm{ml}$

Route: Intramuscular

Frequency: once daily

Duration: 10 days

\section{Azathioprine}

$$
\text { Dose: } 50 \mathrm{mg}
$$

Route: oral

Frequency: Twice daily

Duration: 2 months

\section{Adenosine Triphosphate}

Dose: $30 \mathrm{mg}$

Route: oral

Frequency: once daily, morning

Duration: 2 months

Other given oral form supplements: Cytidine and Uridine Phosphate, Vimpocetine, Huperzine A, L-Theanine and Omega3.

\section{Results}

The patient was examined at the following appointments:

1. After week 2 and after month post-transplantation

2. At the first post-transplantation follow up, the patient declared significant improvement in urination control starting since day 5. She was able to fully control her bladder function. She also showed around $80 \%$ improvement in dizziness. She was able to restart one hour daily neurorehabilitation physiotherapy.

3. After month 1 post-transplantation, the physiotherapist noticed a recognizable gradual decrease in the spasticity and tonicity. The patient continued with a stable improvement in the dizziness.

4. After month 2 post-transplantation, authors noticed more improvement in the state of hypertonicity, but a great progress in the patient's speech abilities. On the other side the patient claimed to have less swallowing problems. Body balance started to be more accentuated; a decrease in the Astasis was registered.

5. After month 3 post-transplantation, both the physiotherapist and the patient noticed a minor improvement in the muscular strength. The dizziness totally disappeared.

6. A measurement of her spasticity showed a change at the Ashworth's scale from level 4 before the treatment with ASCT to level 3 in all limbs. The patient also claimed that she felt no more fatigue in the pre-noon period. Also during this control examination, authors noticed an abrupt disappearance of the diplopia. Numbness and tingling have disappeared as well.

7. After month 4 post-transplantation, progress continued on all previously mentioned levels. The patient remarked an improved in the sight where blurry vision became almost unnoticeable. 
8. After month 6 and 8 post-transplantation, the patient showed stability with no regression of her previous improvements.

9. At 10 months post transplantation, no further improvements were shown but a noticeable stability was recorded. Progression was shown in the Table 1.

\section{Discussion}

MS is a disease characterized by multifocal areas of demyelination in the brain and spinal cord, with associated inflammatory cell infiltrates, reactive gliosis, and axonal degeneration. It typically presents in young adults with episodic neurologic dysfunction. Although the exact origin of MS remains enigmatic, evidence suggests that it is an immunemediated attack on myelin, with secondary disruption of axons leading to progressive disability over time in most afflicted patients. (Source: Cecil Medicne: $24^{\text {th }}$ Edition.: 2348)

This paper is focused on the hopeful treatment of longstanding MS with ASCT, where some of the symptoms and signs may significantly regress, even after a chronic behavior of the disease complications.

In the postoperative period, progressive improvement of the patient has been noticed. The patient progressively improved in her everyday living, along with a fast disappearance of the post-operative headache and excessive urination.

Two weeks after the transplantation, authors noticed remarkable decrease of the long standing vertigo subtype of dizziness; that was due to impairment in spatial perception and stability. Authors concluded that neurotrophic stem cells factors helped with the reinforcement of coordination between spatial and visual inputs; hence the dizziness pathophysiology was reversed.

Detrusor-sphincter dyssynergia, a urinary incontinence disorder is known to be present in as high as $80 \%$ of the MS patients [3]; this is due to the neurogenic detrusor overactivity [5]. Incontinence was greatly reduced since the first days post therapy, where this therapy helped with the gain of control over the muscle activities and responsiveness. These rapid positive results are also due to stem cell neurotrophic factors, causing a constant improvement for the whole follow up period.

After the first month follow up, a muscle rigidity reduction was present along with a noticeable gain of speech abilities and swallowing as described by the assessors and the patient. It is known that hypertonia is due to an imbalance in the electrical signals coming from the brain and spinal cord could lead to severe hypokinesia.

Considering speech and swallowing, the problem originates from the lesions in the brain stem that reach the function of the tongue along with esophageal muscles [6], as noticed, stem cell therapy helped with the reconstruction of nerve connections thus diminishing the clinical picture.

After the second month post-transplantation, the decrease in spasms measured by Ashworth's scale was probably due to a repair of demyelinated axons. Cortical and spinal neuronal demyelination has been proven to be the main cause of motor muscle spasticity [4]. The gain of control may originate from neuronal function improvement in the corticospinal tract. Mesenchymal Stem Cells which reside in the bone marrow buffy coat are known to exert stromal bystander immunemodulatory, neuroprotective and eventually remyelinating activities in the damaged CNS [7]. At the same time the patient showed a total eclipse of her Paresthesia. It is the coherent period to the spino-thalamic connections to respond to the neuro- regenerative process. Many other improvements happen during the third month post-transplantation; the patient continued with the recovery including visual coherence; it is known that multiple sclerosis affected patient lack of vision coherence, thus, having double vision (Diplopia) [8]. Authors think that post therapeutic image formation, was provided by the stem cell stabilization of visual coherence.

From the fourth till the twelfth month, Astasis, which is the lack of motor coordination, the inability to walk, to stand or even to sit without assistance, has cardinally improved. Despite the fact the patient couldn't stand up alone and even though she presented a walking inability caused by the chronic mechanical joints complications, authors considered the improvement an important factor in fixing the depressive state the patient was in before approaching her treatment.

After a nine month period, the patient showed a massive progress in the decrease MS clinical picture; it was noticed that all previous improvements were more accentuated, and at one year follow up, the improved neurological status was still observed. Authors discerned a state of plateau starting from the tenth month post-transplantation.

A brain MRI done one year after transplanation showed no disease progression; new demyelination plaques or deterioration by mean of old sclerotic lesion widening (Table 2).

\begin{tabular}{|c|c|c|c|c|c|c|c|c|c|}
\hline \multirow{2}{*}{ Clinical Picture } & \multicolumn{9}{|c|}{ Follow Up } \\
\hline & Week 2 & Month 1 & Month 2 & Month 3 & Month 4 & Month 6 & Month 8 & Month 10 & Month 12 \\
\hline Neur. bladder & +++ & & & & & & & & \\
\hline Dizziness & + & ++ & ++ & +++ & & & & & \\
\hline Hypertonia & & + & + & & & & & & \\
\hline Headache & & ++ & +++ & & & & & & \\
\hline Paresthesias & & & + & ++ & & & & & \\
\hline Spasms & & & + & ++ & & & & & \\
\hline Dysarthria & & & +++ & & & & & & \\
\hline Dysphagia & & & +++ & & & & & & \\
\hline Astasis & & & + & + & + & ++ & ++ & +++ & \\
\hline Diplopia & & & + & +++ & & & & & \\
\hline Weakness & & & & + & + & + & + & & \\
\hline Blurry vision & & & & + & +++ & & & & \\
\hline
\end{tabular}

Table 1: Post-transplantation occurrence and duration of progression in each particular symptom and sign. "+" indicates the end-result improvement before the stabilization state, good improvement $(+)$, very good $(++)$, excellent $(+++)$. 
Citation: Abi Chahine NH, Rached JR, Abdelkarim AF, Hamade AA, Zoghbi VV (2015) Treatment of Long Standing Multiple Sclerosis with Regentime Stem Cell Technique. J Stem Cell Res Ther 5: 299. doi:10.4172/2157-7633.1000299

\begin{tabular}{|c|c|}
\hline Hauser Ambulation Index & From 8.5 to 8.0 \\
\hline $\begin{array}{c}\text { Kurtzke Expanded Disability Status } \\
\text { Scale (EDSS, Kurtzke, 1983) }\end{array}$ & From 8.5 to 8.0 \\
\hline $\begin{array}{c}\text { Disease Steps (DS, Hohol et al 1995) } \\
\text { Bladder Control Scale (BLCS, Turnbull } \\
\text { et al 1992) }\end{array}$ & $\begin{array}{c}\text { Fo change, stayed at } 6 \\
\text { And fully controllable (0) after } 2 \text { months }\end{array}$ \\
\hline Modified fatigue impact scale (MFIS-5) & Improvement from 19 to 8 \\
\hline Pain Effects Scale (PES) & Improvement from 6 to 20 \\
\hline Impact of Visual Impairment Scale (IVIS) & Improvement from 10 to 4 \\
\hline
\end{tabular}

Table 2: List of measured and assessed MS scales (The national multiple Sclerosis Society).

\section{Conclusion}

We concluded that the procedure of bone marrow derived stem cell transplantation (ASCT) shows potential to be a treatment for long standing, advanced multiple sclerosis regardless to the disease duration. This is due to the progressive nature of the disease, where lesions are spread all along its natural history and maybe the newer ones are getting the most benefit out of this therapy.

\section{References}

1. Abi Chahine NH (2015) How to Maximize the Success of Stem Cell Autografts for Neuroregeneration. J Stem Cell Res Ther 5: 271.
2. Goldenberg MM (2012) Multiple sclerosis review. P T 37: 175-184. [Pubmed]

3. Stankovich Elu, Borisov VV, Demina TL (2004) [Tamsulosin in the treatment of detrusor-sphincter dyssynergia of the urinary bladder in patients with multiple sclerosis]. Urologiia 4: 48-51. [PubMed]

4. Currie R (2001) Spasticity: a common symptom of multiple sclerosis. Nurs Stand 15: 47-52. [PubMed]

5. Haab F (2014) Chapter 1: The conditions of neurogenic detrusor overactivity and overactive bladder. Neurourol Urodyn 33 Suppl 3: S2-5. [PubMed]

6. Buchholz DW (1994) Neurogenic dysphagia: what is the cause when the cause is not obvious? Dysphagia 9: 245-255. [PubMed]

7. Rivera FJ, Aigner L (2012) Adult mesenchymal stem cell therapy for myelin repair in multiple sclerosis. Biol Res 45: 257-268. [PubMed]

8. Kemenyova P, Turcani P, Sutovsky S, Waczulikova I (2014) Optical coherence tomography and its use in optical neuritis and multiple sclerosis. Bratisl Lek Listy 115: 723-729. [PubMed]

9. Hauser SL (2008) Multiple sclerosis and other demyelinating diseases. In Fauci AS, Braunwald E, Kasper DL, Hauser SL, (eds). Harrison's Principles of Internal Medicine. 17th ed. II. New York: McGraw-Hill Medical 2611-2621.

10. Cree BAC (2007) Multiple sclerosis. In: Brust JCM, editor. Current Diagnosis and Treatment in Neurology. New York: Lange Medical Books/McGraw-Hill Medical. 